\title{
A PRODUÇÃO CIENTÍFICA SOBRE JOGOS DIGITAIS NA EDUCAÇÃO FÍSICA ESCOLAR: O QUE DIZEM OS PERIÓDICOS NACIONAIS?
}

\author{
SCIENTIFIC PRODUCTION ABOUT DIGITAL GAMES IN SCHOOL PHYSICAL EDUCATION: WHAT DO \\ NATIONAL JOURNALS SAY?
}
PRODUCCIÓN CIENTIIFICA SOBRE JUEGOS DIGITALES EN LA EDUCACIÓN FÍSICA ESCOLAR: ¿QUÉ DICEN LAS REVISTAS NACIONALES?

\author{
José Ricardo Lopes Ferreira \\ Mestre em Educação (PPGE/UFAL) Docente do curso de Educação Física (Estácio/FAL). \\ E-mail: r2ferreira.edf@gmail.com. \\ Orcid: http://orcid.org/0000-0001-7921-8413
}

\author{
Fernando Silvio Cavalcante Pimentel \\ Doutor em Educação (UFAL) Docente do Programa de Pós-Graduação em Educação (UFAL). \\ E-mail:prof.fernandoscp@gmail.com . \\ Orcid: http://orcid.org/0000-0002-9180-8691
}

\begin{abstract}
RESUMO
Este artigo se propõe debater a respeito da produção acadêmica-científica inerente aos jogos digitais e a Educação Física Escolar. Para tal, foram analisados artigos científicos publicados nos periódicos nacionais no campo da Educação Física. A pesquisa em tela possui um caráter qualitativo, já que opera uma Revisão Sistemática da Literatura. Como critério para a seleção dos periódicos estudados, foram priorizados aqueles voltados área de estratificação da Educação Física, com Qualis A e B de acordo com a avaliação da CAPES (2013-2016) no recorte temporal compreendido entre 2015 e 2019. Foram selecionados cinco artigos. Observase que os estudos empíricos apresentam uma predileção a jogos que possuem movimentos ativos, como exergames e jogos de realidade aumentada. Os estudos teóricos se ocupam em problematizar os jogos digitais como elementos culturais imateriais que possuem uma linguagem própria capaz de produzir sentidos e significados a partir dos processos interativos. Ademais, foi identificada a necessidade de desenvolver estudos nos âmbitos dos serious games e dos e-Sports. Por fim, sugere-se uma RSL mais abrangente, contemplando os anais de eventos e as teses e dissertações.
\end{abstract}

Palavras-chaves: Aprendizagem. Educação física escolar. Cultura digital. Educação básica.

\section{ABSTRACT}

This article proposes to debate about the academic scientific production inherent to digital games and Physical Education in Schools. To this end, scientific articles published in national journals in the field of Physical Education were analyzed. The screen research has a qualitative character, since it operates a Systematic Literature Review. As a criterion for the selection of the studied journals, priority was given to those focused on the stratification area of Physical Education, with Qualis A and B according to the CAPES assessment (2013-2016) in the time frame between 2015 and 2019. Five articles were selected. It is observed that empirical studies have a predilection for games that have active movements, such as exergames and augmented reality games. Theoretical studies are concerned with problematizing digital games as immaterial cultural elements that have their own language capable of producing senses and meanings based on interactive processes. In addition, the need to develop studies in the areas of serious games and e-Sports was identified. Finally, a more comprehensive RSL is suggested, covering the annals of events and theses and dissertations. 
Keywords: Learning. School physical education. Digital culture. Basic education.

\section{RESUMEN}

Este artículo propone debatir sobre la producción científica académica inherente a los juegos digitales y la Educación Física en las Escuelas. Para ello, se analizaron artículos científicos publicados en revistas nacionales en el campo de la Educación Física. La investigación de pantalla tiene un carácter cualitativo, ya que opera una Revisión Sistemática de la Literatura. Como criterio para la selección de las revistas estudiadas, se priorizaron las enfocadas al área de estratificación de Educación Física, con Qualis A y B según la evaluación CAPES (2013-2016) en el marco temporal entre 2015 y 2019.Se seleccionaron cinco artículos. Se observa que los estudios empíricos tienen predilección por los juegos que tienen movimientos activos, como los exergames y los juegos de realidad aumentada. Los estudios teóricos se preocupan por problematizar los juegos digitales como elementos culturales inmateriales que tienen un lenguaje propio capaz de producir sentidos y significados a partir de procesos interactivos. Además, se identificó la necesidad de desarrollar estudios en las áreas de juegos serios y e-Sports. Finalmente, se sugiere una RSL más completa, que cubra los anales de eventos y tesis y disertaciones.

Palabras-claves: Aprendizaje. Educación física escolar. Cultura digital. Educación básica.

\section{INTRODUÇÃO}

A Educação Física é um componente curricular de caráter obrigatório na Educação Básica, presente na área de linguagens (BRASIL, 1998). De acordo com a Base Nacional Comum Curricular (BRASIL, 2018), a Educação Física, tem como objeto de estudo as diferentes práticas corporais, considerando seus aspectos históricos, sociais e políticos. Em meio a tais práticas corporais evidencia-se a presença do jogo, considerado um elemento cultural que possui a capacidade de se manifestar sob diversas formas de atividades lúdicas.

Uma das formas mais populares de jogo no contexto da Cultura Digital são os jogos digitais, entendidos aqui como atividades lúdicas desenvolvidas a partir de aparatos audiovisuais e que tendem a serem baseados em histórias. É valido ressaltar que devido as suas potencialidades, os jogos digitais tem atravessado a fronteira do lúdico e marcando presença em outras atividades do nosso cotidiano. Produzindo novas formas de interagir tanto com o digital quanto com a vida real em diversas áreas como o marketing, a administração e psicologia (Blinded Review).

Não obstante, os jogos digitais tem sido discutidos como alternativas pedagógicas nos processos de ensino e aprendizagem, nos mais diferentes níveis, por conta do seu potencial como atividade lúdica e motivadora (RAMOS; CRUZ, 2018). Contudo, alerta Alves (2008), que não se trata de incorporar os jogos digitais as aulas para deixa-las menos 
monótona. É preciso que os jogos sejam abordados como elementos culturais que possuem representação para os estudantes.

Nesse sentido, se faz imperativa a problematização de tal fenômeno no âmbito da Educação Física escolar, não apenas por ser uma das principais fontes de entretenimento dos jovens. Mas, por levar em consideração que os jogos digitais tem como característica promover novos sentidos e significados proporcionando novos modos de interação dentro e fora do ambiente digital, ressignificando a corporeidade e a Cultura Corporal de Movimento.

Cientes da relevância dos jogos digitais no cenário atual, dada sua presença em diversos campos, para além do entretimento, sobretudo a educação. Surge-nos a inquietação e compreender de que forma os jogos digitais são incorporados às aulas de Educação Física. Para isso, recorremos aos estudos científicos, adotando como fonte principal de pesquisa os artigos publicados nos periódicos especializados. Portanto, este estudo foi orientado pela seguinte questão: Quais indícios ou evidências que as pesquisas publicadas em periódicos nacionais da área da Educação Física evidenciam a respeito da relação dos jogos digitais com a Educação Física Escolar?

Nesse caminho, a pesquisa se objetivou a identificar e analisar de forma sistêmica os estudos científicos a respeito das relações entre os jogos digitais e a Educação Física Escolar. De modo especifico, objetivamo-nos a identificar com quais perspectivas os jogos digitais são incorporados às aulas de Educação Física, quais os principais tipos de jogos e as principais abordagens teóricas que perpassam tais prática s pedagógicas.

$\mathrm{Na}$ busca de alcançar os objetivos propostos foi adotada uma metodologia de abordagem qualitativa do tipo Revisão Sistemática se trata de um método que visa realizar um levamento do estudos já publicados a partir de um determinado tema, permitindo um olham amplo para as evidências científicas já produzidas (COSTA; ZOLTOWSKI, 2014).

Neste artigo utilizamos como fonte principal de busca os artigos científicos publicados nos principais periódicos nacionais no campo de Educação Física. Para isso, como fonte de pesquisa foi utilizado o sistema de avaliação Qualis da Coordenação de Aperfeiçoamento de Pessoal de Nível Superior (CAPES) que classifica os periódicos nacionais. Foi utilizada como referência a estratificação $A 1, A 2, B 1$ e B2 referente ao quadriênio 2013-2016 no campo da Educação Física. 
Diante do que foi apresentado, este artigo foi organizado em duas partes. A primeira delas, diz respeito ao percurso metodológico em que é apresentado o protocolo da RSL e os caminhos trilhados para a seleção dos periódicos consultados e dos artigos analisados. Na segunda partes é apresentada uma análise crítica e sistematizada dos artigos selecionados, considerando os tipos de estudo, público participante, jogos estudados, abordagens resultados obtidos e possíveis desdobramentos.

\section{Metodologia}

O percurso metodológico deste estudo foi orientado por uma pesquisa bibliográfica do tipo revisão sistemática de literatura (RSL), que de acordo com Costa e Zoltowski (2014) se refere a reunião e avaliação crítica e sintética de resultados de diferentes estudos. Nesse sentido, a finalidade deste tipo de estudo é proporcionar uma visão abrangente para a literatura acadêmica para determinado fenômeno.

Diante disso, para coletar os dados necessários, a RSL exige um percurso investigativo que siga um rigoroso protocolo pré-determinando. Isso contribui para que não haja lacunas no estudo respeitando o rigor científico. Para tanto, está pesquisa foi conduzida a partir de um protocolo apresentado por Costa e Zoltowski (2014) conforme as etapas sistematizadas no quadro 1.

Quadro 1: Protocolo da Revisão Sistemática de Literatura.

\begin{tabular}{|c|l|}
\hline Etapa & \multicolumn{1}{c|}{ Descrição } \\
\hline Etapa 1 & Delimitação da questão a ser pesquisada; \\
\hline Etapa 2 & Escolha das fontes de dados; \\
\hline Etapa 3 & Eleição das palavras-chave para a busca; \\
\hline Etapa 4 & Seleção de artigos pelo resumo, de acordo com critérios de inclusão e exclusão; \\
\hline Etapa 5 & Extração dos dados dos artigos selecionados; \\
\hline Etapa 6 & Avaliação dos artigos; \\
\hline Etapa 7 & Síntese e interpretação dos dados \\
\hline
\end{tabular}

Fonte: Costa e Zoltowski (2014).

Como ponto de partida, a primeira etapa do protocolo se tratou da definição das questões a serem pesquisadas, as quais suscitaram do objetivo principal proposto deste estudo, foram elas: 
- Q1: Quais indícios e evidências as pesquisas apresentam em relação aos jogos digitais e a Educação Física escolar?

- Q2: Em quais perspectivas os jogos digitais são incorporados as aulas de Educação Física?

- Q3: Quais tipos de jogos digitais foram adotados nas pesquisas?

Para definir os periódicos que seriam a fonte principal de dados deste estudo, foi adotado o sistema de avaliação Qualis-Capes disponível na Plataforma Sucupira, que os classifica com base em critérios pré-determinados em uma estratificação que vai de $C$ até A1. A busca foi determinada pela estratificação referente ao quadriênio 2013-2016 no campo acadêmico científico da Educação Física. Para refinar as buscas e alinha-la ao objetivo principal deste estudo, foram determinados critérios para inclusão do periódico nas buscas, a saber: (i) Possuir estratificação B2, B1, A2 e A1 (Qualis-Capes); (ii) Ter origem nacional; (iii) Ser editorado em língua portuguesa; (iv) Possuir todos os números disponíveis em sua plataforma digital; (v) Possuir como escopo de divulgação científica o campo acadêmico da Educação Física. Após a busca e aplicação dos critérios, foram selecionados oito periódicos que foram eleitos como fonte de busca bibliográfica conforme a quadro a seguir.

Quadro 2: Periódicos selecionados para a busca de dados.

\begin{tabular}{|c|c|c|}
\hline Periódicos & Editoria & Qualis \\
\hline Revista Brasileira de Ciências do Esporte & CBCE & B1 \\
\hline Revista Motrivivência & UFSC & B2 \\
\hline Revista Movimento & UFRGS & A2 \\
\hline Revista Licere & UFMG & B2 \\
\hline Revista Pensar a Prática & UFG & B2 \\
\hline Revista Brasileira de Ciências e Movimento & PUC/DF & B2 \\
\hline Journal of Phisical Education & UEM & B1 \\
\hline
\end{tabular}

Fonte: dados da pesquisa (2020).

A próxima etapa da RSL se consistiu na definição das strings de busca para a extração dos dados. Para cumprir essa etapa foram escolhidos os seguintes termos: "Jogos digitais"; “Jogos Eletrônicos”, “Exergames", “e-Sports”, “Esportes Eletrônicos” e "Games". A extração dos dados ocorreu de forma manual, para isso as plataformas digitais dos periódicos selecionados foram visitadas uma a uma. A busca ocorreu em todos os números das revistas abrangendo as publicações de fluxo contínuo, dossiês e edições 
suplementares disponíveis no recorte temporal compreendido entre os anos de 2015 e 2019.

As buscas nos periódicos aconteceram no período de 01 de março de 2020 a 01 de abril de 2020. A seleção se deu com base na leitura do título e dos resumos dos estudos. Para o devido refinamento da pesquisa foram aplicados os seguintes

critérios:

Critérios de inclusão:

1 - Artigos originais ou ensaios;

2 - Ser publicado no recorte temporal 2015/2019;

3 - Estar disponível em língua portuguesa;

4 - Contemplar a os jogos digitais e Educação Física no âmbito da educação;

Critérios de exclusão:

1 - Ser estudo de revisão sistemática de literatura ou estado da arte;

2 - Estudos desenvolvidos no campo não formal da Educação Física.

\section{Resultados e discussões}

Nesta etapa os estudos selecionados foram sistematizados para responder as perguntas que norteiam a RSL. Os dados da busca de identificação elegeram 22 estudos obtidos por meio das strings de buscas.

Figura 1: Resultado da busca 


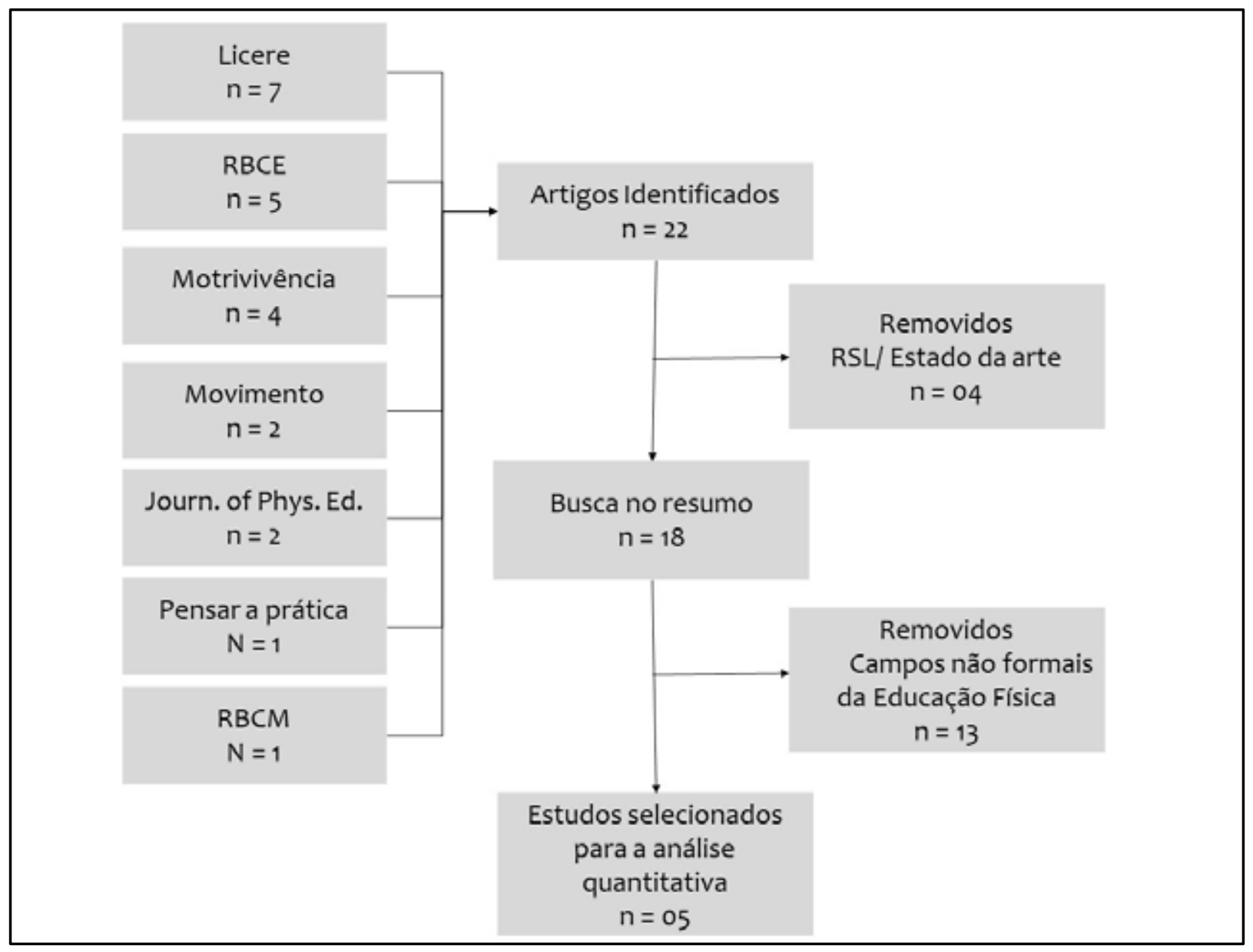

Fonte: dados da pesquisa (2020).

Os estudos encontrados foram submetidos aos critérios de inclusão e de exclusão pré-determinados representado no fluxograma (Figura I). Após a aplicação dos critérios de inclusão e exclusão foram removidos 17 (dezessete) estudos, dos quais 4 (quatro) revisões sistemáticas de literatura, e 13 (treze) estudos realizados nos campos não formais da Educação Física, como hospitais, hotéis, laboratórios de performance e rendimento. Portanto, para a análise dos dados foram eleitos 5 (cinco) estudos. Após busca e seleção, foram realizados os downloads e a leitura dos trabalhos em sua integra, em seguida, foram sistematizados para a análise qualitativa com base nas perguntas norteadoras desta RSL.

\section{Quanto aos objetivos dos estudos}

Como é possível observar no Quadro 3, os artigos selecionados buscam compreender, analisar, identificar e debater a respeito das relações entre jogos digitais, ensino e aprendizagem de esportes, e desenvolvimento de habilidades sociais e valores no contexto da Educação Física. 
Evidencia-se a predileção a respeito dos jogos que incentivam o movimento ativo, como os exergames (FINCO et al., 2015; CAMUCl et al. 2015) e de Realidade Aumentada (RA) (CRUZ JÚNIOR, 2017a). Para Araújo et. al. (2018), as reações produzidas no contexto do jogo, são capazes de ressignificar a cultura corporal do movimento, produzindo novas significações e por consequência novos modos de conceber experiências corporais no contexto da cultura digital.

Quadro 3: Objetivos dos estudos analisados

\begin{tabular}{|c|c|}
\hline Referência & Objetivo \\
\hline $\begin{array}{l}\text { Finco et al. } \\
\text { (2015) }\end{array}$ & $\begin{array}{l}\text { Compreender de que maneira o uso de exergames pode contribuir com } \\
\text { a prática de atividade física e com o desenvolvimento de habilidades } \\
\text { sociais. }\end{array}$ \\
\hline $\begin{array}{l}\text { Camuci et al. } \\
\text { (2017) }\end{array}$ & $\begin{array}{l}\text { Analisar o jogo de videogame Kinect Sports (Xbox 360), relacionado } \\
\text { ao atletismo, verificando as proximidades e distanciamentos em } \\
\text { relação à modalidade esportiva oficial e suas possibilidades } \\
\text { pedagógicas }\end{array}$ \\
\hline $\begin{array}{l}\text { Cruz Júnior } \\
\text { (2017a) }\end{array}$ & $\begin{array}{l}\text { Problematizar as relações entre jogos digitais, educação e movimento } \\
\text { por intermédio do game Pokémon Go e à luz de tendências } \\
\text { emergentes no âmbito da aprendizagem móvel e da indústria do } \\
\text { entretenimento. }\end{array}$ \\
\hline $\begin{array}{l}\text { Cruz Júnior } \\
\text { (2017b) }\end{array}$ & $\begin{array}{l}\text { Discutir a ludificação da cultura, evidencia e problematiza suas } \\
\text { implicações no que diz respeito às relações entre jogos digitais e } \\
\text { educação }\end{array}$ \\
\hline $\begin{array}{c}\text { Constantino et al. } \\
(2017)\end{array}$ & $\begin{array}{l}\text { Identificar o perfil do uso de TICs por alunos do ensino fundamental e } \\
\text { verificar a relação entre os valores percebidos por esses alunos na } \\
\text { prática de JEs com os valores desenvolvidos nas aulas de Educação } \\
\text { Física. }\end{array}$ \\
\hline
\end{tabular}

Fonte: dados da pesquisa (2020).

Os objetivos apresentados nos estudos, mostram-se pertinentes haja vista a preocupação das mudanças que a cultura digital promove na sociedade em geral e sobretudo nos contextos educacionais (PIMENTEL, 2018). A visibilidades proporcionada permitem a reflexão sobre a incorporação dos jogos digitais como um elemento cultural repleto de sentidos e significados (ALVES, 2008).

\section{Quanto as abordagens metodológicas e frequência de publicação}

A respeito da abordagem metodológica evidenciou-se a presença de dois ensaios (CRUZ JÚNIOR, 2017a; 2017b), dois estudos de abordagem qualitativa, sendo um do tipo relato de experiência (FINCO et al., 2015), e outro não especificado (CAMUCl et al., 2017) 
ambos estudos adotaram como técnica de coleta de dados a observação participante e a entrevista semiestruturada. Por fim, o estudo de Constantino et al. (2015), adotou uma abordagem quanti-qualitativa do tipo descritiva, em que adotou como método de coleta de dados uma entrevista semiestruturada (CONSTANTINO et al., 2015).

A respeito da frequência relativa de publicação é valido ressaltar que apesar do recorte proposto na pesquisa compreender os anos de 2015 a 2019, observa-se a concentração de publicações anos de 2015 (2) e 2017 (3). Para além disso, que enquanto veículo de divulgação científica que as publicações foram oriundas das revistas: Motrivivência (2); Revista Movimento (1); Revista Brasileira de Ciências do Esporte (1) e Revista Pensar a Prática (1).

\section{Quanto as principais evidências}

Após a leitura dos cinco artigos que compuseram esta RSL para a organização das principais características, foram estruturadas duas categorias de análise de dado. A primeira delas "práticas pedagógicas" que foram reunidas pesquisas empíricas que discutem uso didático dos jogos digitais no contexto dos processos de ensino e a aprendizagem. A segunda categoria, "pressupostos para a incorporação dos jogos digitais" trata das reflexões teóricas a respeito da incorporação dos jogos digitais na educação como elemento cultural.

\section{Práticas pedagógica}

Nesta categoria, foram reunidos dois estudos que se tratam de práticas pedagógicas e reflexões a respeito dos jogos digitais para fins educacionais. Os estudos de Camuci et al. (2017) e Finco et al. (2015), apresentaram experiências a respeito da incorporação do exergames por meio do jogo Kinect Sports (Xbox 360) no âmbito do ensino dos esportes (CAMUCl et al., 2017) e em um projeto extra classe (FINCO et al., 2015).

Camuci et al. (2017), se propôs a averiguar as possibilidades pedagógicas do jogo em questão para o ensino do atletismo e as proximidades e distanciamentos em relação a modalidade oficial. O estudo aponta a incorporação do videogame no contexto escolar oferece ao professor de Educação Física a possibilidade de explorar o amplo universo do 
atletismo tem potencial motivador para incorporar o processo de ensino e aprendizagem do atletismo pode meio de um trabalho diferenciado mediado pelas tecnologias.

Outro estudo, desenvolvido por Finco et al. (2015), estudou sobre a incorporação do uso dos jogos digitais nas aulas de Educação Física com a criação do laboratório de exergames como um espaço complementar para as aulas de Educação Física. A pesquisa buscou entender de que maneira o uso dos exergames nas aulas de Educação Física podem colaborar com a prática de atividade física e o desenvolvimento de habilidades sociais.

Para Camuci et al. (2017) e Finco et al. (2015) os exergames incorporados no contexto escolar são capazes de potencializar as aulas de Educação Física motivando a participação das práticas nos processos de ensino e aprendizagem. A respeito disso, Ramos e Cruz (2017, p. 41) destacam que:

os jogos oferecem um campo de experimentação que possibilitam a oportunidade de superar uma condição a priori, por meio da exploração, ação e da reflexão, muitas vezes de forma tão envolvente que tornam a aprendizagem mais divertida e atraente.

Além disso, Finco et al. (2015) destacam que no contexto da intervenção os exergames promoveram a colaboração entre os estudantes, essa evidência está de acordo com McGonigal (2012) que afirma que os jogos digitais permitem uma maior conectividade social dentro e fora do contexto do jogo. a e estimulando o trabalho em grupo. A pesquisa ainda identificou que a vivência com jogos digitais estimulou os estudantes a buscarem novos conhecimentos a respeito de atividade física e dos esportes fora do contexto do jogo, o que de acordo com Albuquerque (2018), se configura em uma aprendizagem tangencial ${ }^{1}$ que é quando o jogador, motivado por algum elemento do jogo, vai em busca de outras fontes para ampliar determinado conhecimento.

\section{Pressupostos para a incorporação dos jogos digitais}

Nesta categoria, foram reunidos estudos que fazem uma reflexão a respeito da incorporação dos jogos digitais nos contextos educacionais como elemento cultural, vislumbrando suas potencialidades para além de uma incorporação instrumental.

\footnotetext{
${ }^{1} \mathrm{O}$ conceito de aprendizagem tangencial não se refere a buscas informações a respeito do jogo em si, mas de elementos que envolvam dimensões culturais além do jogo (ALBUQUERQUE, 2020).
} 
A pesquisa de Constantino et al. (2015), teve como objetivo, verificar a percepção de valores presentes nos jogos digitais e os desenvolvidos nas aulas de Educação Física. A pesquisa identificou que os jogos estudados (The Sims, GTA - Grand Theaf Auto, FIFA/PES; Minecraft), na percepção dos alunos, desenvolvem os seguintes valores de organização, gerenciamento e tomada de decisões; honestidade, paz e respeito; trabalho em equipe e cooperação; pensamento estratégico, criatividade e solução de problemas. De acordo com Ramos e Cruz (2017), os jogos digitais podem ser muito uteis para desenvolver os aspectos atitudinais uma vez que envolvem valores atitudes e normas, pois neles assumimos papéis, realizamos ações e sofremos suas consequências, interagimos com outros jogadores e agimos de acordo com as regras definidas.

Outro estudo, desenvolvido por Cruz Júnior (2017a), debateu as relações entre jogos digitais, educação, e movimento a partir das tendências emergentes da aprendizagem móvel e da indústria do entretenimento por meio do jogo Pokémon Go (Niantic). O estudo aponta que os jogos digitais por meio das mídias móveis podem contribuir para compreensão dos novos modos de agir e pensar, compreender as formas específicas de movimento que se relacionam com as possibilidades da Realidade Aumentada, ressignificando a cultura corporal de movimento.

O último estudo desta categoria, também desenvolvido por Cruz Júnior (2017b), se concentrou em debater as relações entre os jogos digitais, a cultura e a educação. A discussão tem como cenário a maneira que as pessoas lidam com a separação entre o jogo e o mundo real e as demandas formativas que suscitam neste contexto. O estudo destaca duas categorias criadas sistematicamente para transpor o círculo mágico, que é a gamificação e os jogos de realidades alternativas. Em linhas gerais, ambas categorias buscam promover mudanças reais nos modos de vida de seus participantes, por meio da utilização das mecânicas e linguagem dos jogos.

Para tanto, Cruz Júnior (2017b), sugere que se desenvolva um olhar para os jogos digitais como materialidade simbólica, ou seja, repleto de sentidos e significados que se resulta das interações humanas. Isso pois os jogos digitais representam uma linguagem autônoma que traz consigo modos singulares para assimilar e interpretar os significados dentro e ao redor dos contextos lúdicos interativos.

Nesta linha, Cruz Junior (2017b), Ramos e Cruz (2018) e [Blinded Review], consente na necessidade de reorganizar as abordagens teóricas no âmbito da educação superando 
o seu uso instrumental, voltado apenas para descontrair as abordagens de conteúdos curriculares de modo a considerar a incorporação dos Jogos Digitais na Educação a partir de um olhar cultural valorizando os sentidos e significados construídos pelos jogadores.

\section{CONSIDERAÇÕES FINAIS}

Este estudo se propôs a analisar a produção acadêmica brasileira acerca dos jogos digitais no campo acadêmico científico da Educação Física no âmbito da Educação. Para tanto, foi analisada a produção nos últimos cinco anos em oito revistas de estratificação Qualis A e B, no escopo de Educação Física. Após a aplicação dos critérios de inclusão e exclusão, foram selecionados cinco trabalhos.

Diante do que foi apresentado, os dados produzidos sugerem que o campo da Educação Física tem se dedicado a problematizar o fenômeno dos jogos digitais em contextos educacionais, enfatizando as relações entre os jogos digitais e os processos de ensino e aprendizagem, o que resultou na estruturação de duas categorias de análise: possibilidades pedagógicas; e pressupostos para incorporação dos jogos digitais na educação. Este debate suscitou algumas considerações.

Primeiramente, identificou-se o desenvolvimento de pesquisa empíricas sobre a incorporação dos jogos digitais nas aulas de Educação Física escolar. É notável a predileção pelos jogos digitais de movimento ativo, como os exergames. Os estudos apontam a presença dos jogos digitais como elementos culturais no cotidiano dos estudantes é um elemento que favorece a incorporação desses jogos nas aulas.

Neste sentido, outro elemento que merece destaque, diz respeito as possibilidades de construção do conhecimento nos ambientes digitais com incentivo da ludicidade. Além disso, destaca-se que os jogos digitais promovem um ambiente favorável para colaboração. A respeito dos estudos teóricos, foi possível evidenciar a presença de dois ensaios que problematizam as relações entre os jogos digitais, a ludicidade e a educação. O ponto de partida de ambos estudos é o rompimento do círculo mágico, que é a linha tênue que separa a vida real do jogo. Cada vez mais, o jogo está interagindo com o mundo real, o que proporciona uma nova maneira de lidar com o mundo. 
Observa-se nos estudos a preocupação de incorporar os jogos digitais como elementos culturais considerando as relações dos estudantes com este artefato, de modo a superar a sua utilização maniqueísta. De um modo geral, sugere-se que os jogos digitais no âmbito da educação superem a relação minimalista de um elemento lúdico a ser agregado no currículo. É imperativo que diante de toda a representatividade dos jogos digitais nos dias de hoje sejam problematizados no âmbito da educação como um elemento cultural imaterial, que possui linguagem própria, o que por sua vez proporciona novos modos de interagir e lidar com o cotidiano.

Os resultados aqui apresentados sugerem que os periódicos estudados se apresentam como fonte para divulgação de estudos que abordem os jogos digitais e a Educação Física. Nesse sentido, sugerimos que sejam desenvolvidos outros estudos no âmbito da Educação Física e os jogos digitais, ampliando a possibilidade de compreender de que modo ocorrem suas relações. Assim considerando, as evidências encontradas nessa RSL identificamos como campo promissor para o desenvolvimento de pesquisas, o fenômeno dos e-Sports (esportes eletrônicos), que se trata de uma vertente competitiva dos jogos digitais, visto que neste estudo não

foram encontradas investigações publicadas. Outro campo a ser explorado diz respeito produção de jogos digitais enquanto serious games, que se trata da criação de jogos criados com o propósito educacional específico.

Por fim, é valido ressaltar que este estudo não esgota as possibilidades de pesquisa que envolvem está temática, uma vez que adotamos uma vertente específica de divulgação científica, os artigos publicados em periódicos nacionais. Diante disso, indica-se o desenvolvimento de outros estudos revisão de literatura, de um modo mais abrangente, incluindo, teses e dissertações bem como anais de eventos da área, como também em periódicos de outras bases internacionais.

\section{REFERÊNCIAS}

ALBUQUERQUE, Rafael Marques de. Como a curiosidade pode enriquecer o jogar? In: RAMOS, Daniela Karine; CRUZ, Dulce Marcia. Jogos digitais em contextos educacionais. 1 ed. Curitiba: CRV, 2018. p. 21-42.

ALVES, Lynn. Relações entre os jogos digitais e aprendizagem: delineando percurso. Educação, Formação \& Tecnologias, América do Norte, v. 1, n. 2, dez. 2008, p. 3-10. 
Disponível em: https://eft.educom.pt/index.php/eft/article/view/58 . Acesso em: 20 Set. 2020.

ARAÚJO, Bruno Medeiros Roldão de; et al. O corpo virtualizado nas relações tecnológicas com o esporte nos jogos de vídeo e mídias informacionais. Journal of Physical Education, v. 29, n. 1, fev. 2018, p. 2923. Disponível em: http://www.periodicos.uem.br/ojs/index.php/RevEducFis/article/view/33831 . Acesso em: 14 ago. 2020.

BRASIL, Ministério da Educação. Base nacional comum curricular: educação é a base. Brasília: $\quad$ MEC, 2018. Disponível em: http://basenacionalcomum.mec.gov.br/images/BNCC_EI_EF_110518_versaofinal_site.pdf. Acesso em: 20 set 2020.

BRASIL, Ministério de Educação e do Desporto. Parâmetros Curriculares Nacionais: terceiro e quarto ciclos: Educação Física / Secretaria de Ensino Fundamental. Brasília: MEC/SEF, 1998.

CAMUCI, Guilherme Correa; et al. O jogo de videogame relacionado ao atletismo e suas possibilidades pedagógicas. Motrivivência, Florianópolis, v. 29, n. 50, p. 62-76, abr. 2017. Disponível em: https://periodicos.ufsc.br/index.php/motrivivencia/article/view/21758042.2017v29n5op62. Acesso em: 14 ago. 2020.

CONSTANTINO, Marcio Turini; et al. Perfil e percepção do uso de jogos eletrônicos por alunos do ensino fundamental: relações com a educação física. Pensar a Prática, Goiânia, v. $18, \quad$ n. 4 , out./dez. 2015, p. 848-863. Disponível em: https://revistas.ufg.br/fef/article/download/36492/19784. Acesso em: 14 ago 2020.

COSTA, Angelo Brandeli; ZOLTOWSKI, Ana Paula Couto. Como escrever um artigo de revisão sistemática. IN: KOLLER, Silvia et al. Manual de produção científica. Porto Alegre: Penso, 2014.

JÚNIOR, Gilson Cruz. Temos que pegar? Pokémon Go e as interfaces entre movimento, jogos digitais e educação. Motrivivência, Florianópolis, v. 29, n. especial, dez. 2017, p. 257273. Disponível em: https://periodicos.ufsc.br/index.php/motrivivencia/article/view/21758042.2017V29nespp257. Acesso em: 14 ago. 2020.

JÚNIOR, Gilson Cruz. Vivendo o jogo ou jogando a vida? Notas sobre jogos (digitais) e educação em meio à cultura ludificada. Rev. Bras. Ciênc. Esporte, Porto Alegre, v. 39, n. 3, p. 226-232, Set. 2017. Disponível em: http://www.scielo.br/scielo.php?script=sci_arttext\&pid=S010132892017000300226\&lng=e n\&nrm=iso. Acesso em: 14 ago. 2020.

FINCO, Mateus David; et al. Laboratório de exergames: um espaço complementar para as aulas de educação física. Movimento (ESEFID/UFRGS), Porto Alegre, v. 21, n. 3, jul./set. 2015, p. 687-699. Disponível em: https://seer.ufrgs.br/Movimento/article/view/52435. Acesso em: 14 ago. 2020. 
MCGONIGAL, Jane. A realidade em jogo: por que os games nos tornam melhores e como eles podem mudar o mundo. Rio de Janeiro: Bestseller, 2012.

RAMOS, Daniela Karine; CRUZ, Dulce Marcia. A tipologia de conteúdos de aprendizagem nos jogos digitais: o que podemos aprender? In: RAMOS, Daniela Karine. (Org) Jogos digitais em contextos educacionais. 1 ed. Curitiba: CRV, 2018. p. 21-42.

Recebido em: 20/09/2020

Parecer em: 03/02/2021

Aprovado em: 20/02/2021 